\title{
Mutans Streptococci Count and Salivary Histatin 5 Level in Relation to Early Childhood Caries
}

\author{
Heba k. Salman ${ }^{1}$, Zainab A. Aldhaher ${ }^{2}$ \\ ${ }^{1}$ Master Student, Department of Basic science, College of Dentistry, University of Baghdad, Iraq, \\ ${ }^{2}$ Professor, Department of Basic Science, College of Dentistry, University of Baghdad, Iraq
}

\begin{abstract}
Background: ECC is one of the most common chronic infectious diseases of preschool-aged children (3). Mutans Streptococci (MS) is the cheif microorganism that causes ECC Saliva is a significant factor in the development of teeth decay. Saliva have many innate defense molecules that take part in the protection of oral tissues by either direct antimicrobial effect or interference with microbial colonization. These molecules include antimicrobial peptides AMPs among the main natural antimicrobial proteins of saliva . Salivary histatine-5 (HST-5) is one of the protective factors in saliva that possess anti-bacterial properties against several types of oral bacter. This study aimed to measure the viable count of mutans streptococci and salivary histatin 5 level in relation to early childhood caries.
\end{abstract}

Materials and Method: Sixty three children with ages of 4-5 years old were enrolled in this study. They were divided into two groups; 33 children with severe type of ECC) ategory as the study group and 30 caries free child) as the control group. Unstimulated saliva sample were collected for ms count on mitis bacitracin agar and for evaluation of salivary Histatin 5 level.

Results: Statistical analysis revealed that M.S. count was higher significantly in study group compared to than control group and salivary histatin 5 was significantly higher than the control group.

Keywords: Early childhood caries, Mutans streptococci, histatin 5.

\section{Introduction}

Early childhood caries (ECC) is one of the most common chronic infectious diseases of preschool-aged children, characterized by the destruction of tooth tissues by synergistic complex effects among acids generated from the fermentation of dietary carbohydrates by bacteria and susceptible host factors, such as teeth and saliva ${ }^{(1)}$. Tooth decay of primary teeth in children 71 months of age or younger was regarded to early childhood caries (ECC). In accordance to American Academy of Pediatric Dentistry, ECC is "the finding of one or more decayed (non cavitated or cavitated lesions), missing (due to caries), or filled tooth surfaces in any decedious tooth in a child below the age of six ${ }^{(2)}$. ECC is a multicausal disease that happened due to host, environment, and microorganism as the causative factors (3). Mutans Streptococci (MS) is the cheif microorganism that causes ECC. In the past decade, numeral researches conducted in the relationship between the occurrence of caries and the founding of salivary MS (4). Saliva may transport the bacteria and have a role as a reservoir for the colonization of the bacteria. If the cariogenic bacteria presedant in saliva and plaque, it will raise the acids, which are made by them through the fermentation process of carbohydrate. Then will rise up the colony of the bacteria and begin creating biofilm on tooth surface $^{(5)}$.

One of the fundemantal factors of MS virulence is the potency to give glucan made up by glusyltransferase, which mediated microorganism attachment to the tooth surface along with other protein ${ }^{(6)}$.

Numerous of studies previously have based a positive correlation between MS and $\mathrm{ECC}^{(7)}$. A positive correlation was also found between severity of ECC as measured by the dmft index and high levels of MS counts, indicating that as the number of colonies increased, the number of teeth and surfaces affected by 
decay also increased.Colonization with MS is thus a key event in the pathogenesis of ECC that can be targeted for caries prevention in clinical practice ${ }^{(8)}$.

Increasingly more and more attention is being paid to the potential of saliva as a potent anticaries agent ${ }^{(9)}$. Saliva is a significant factor in the development of teeth decay. Saliva protects the tooth against missing of calcium and phosphate ions from the enamel by creating a dental pellicle. The salivary pellicle acts as a protective barrier and helps in preventing demineralization, promoting remineralization, keeping the oral cavity $\mathrm{pH}$ neutral and cleaning tooth surfaces by washing away remaining food. ${ }^{(1)}$ The development of caries is affected by the physiochemical careteria of saliva, such as $\mathrm{pH}$, salivary flow rate, buffering capacity, varying protein concentrations and other contenant of saliva. Saliva has many innate defense molecules that take part in the protection of oral tissues by either direct antimicrobial effect or interference with microbial colonization. These molecules include antimicrobial peptides AMPs (cathelicidin peptide LL-37, alpha-defensins, betadefensins, histatins and statherin), major salivary glycoproteins (mucins, proline-rich proteins (PRPs) and immunoglobulins) and minor salivary glycoproteins (agglutinin, LF, cystatins and lysozyme). These proteins play specific functional roles in the first line of defense of the oral cavity. ${ }^{(10)}$

Histatins are small cationic peptides made up of at least 12 histidine-rich basic peptides . Histatins (HST)produced in parotid and sublingual salivary glands-are among the main natural antimicrobial proteins of saliva. The HSTgroup includes HST-1, $-2,-3,-4,-5$ and -6 . Salivary histatine-5 (HST-5) is one of the protective factors in saliva; it is a salivary peptide that consists of 24 amino acids produced in parotid and sublingual salivary glands., salivary HST-5 was demonstrated to possess fungicidal and fungistatic properties against Candida albicans and antiviral activity against the human immunodeficiency virus (HIV), in addition to antibacterial properties against several types of oral bacteria ${ }^{(11,12)}$.

\section{Materials and Method}

Sixty three children with ages of 4-5 years old during the period from December 2019 to march 2020 were enrolled in this study. They were divided into two groups; 33 children with severe type of ECC according to Wyne ${ }^{(13)}$ category as the study group and 30 caries free child according to WHO ${ }^{(14)}$ as the control group. They will be selected from pediatric and preventive departments clinics/college of dentistry/Baghdad university Baghdad city.

$3-5 \mathrm{ml}$ of unstimulated saliva was collected by drooling method ${ }^{(15)}$. $1 \mathrm{ml}$ from each sample for microbiological investigation and bacterial culturing then the remaining of each salivary sample was centrifuged for 10 minutes at $1000 \times \mathrm{g}$ at $2.8^{\circ} \mathrm{C}$. The supernatant which is about $1-2 \mathrm{ml}$ was transported to eppendroffs tube with the same number of the child for freezing. The sample was stored at $-20^{\circ} \mathrm{C}$ for further biomarkers detection procedure.

Microbiological Analysis: The collected salivary samples were homogenized for 1 minute using vortex mixer and then ten-fold serial dilutions were performed From dilution 10-3 of salivary samples $0.1 \mathrm{ml}$ was spread microbiological on MSB agar plates. The plates were incubated anaerobically by using a gas pack supplied in an anaerobic jar at $37{ }^{\circ} \mathrm{C}$ for $48 \mathrm{hrs}$, followed by aerobic incubation for $24 \mathrm{hrs}$, at $37{ }^{\circ} \mathrm{C}$.

Identification was done according to colony morphology, Gram stain reaction, Biochemical test, catalase test. Carbohydrate fermentation test for M.S and bacterial colony count was also done ${ }^{(16)}$

Biomarker Detection: The level of salivary histatin 5 was estimated by using commercially available sandwich enzyme-linked immunosorbent assay (ELISA) kit and performed as recommended in leaflet with kit (MyBiosource; USA).

Statically analysis will be carried out using statistical package for social sciences (SPSS) version 21. Descriptive statistics using: frequencies, mean and standard error in addition to the following statically test: Independent sample $\mathrm{T}$ test, correlation coefficient (r), chi-square. 


\section{Results and Discussion}

Table 1: Mutans Streptococci count $\left(\mathrm{CFU} / \mathrm{ml}^{\circ} \times \mathbf{1 0}^{3}\right)$ in early childhood group and caries free group.

\begin{tabular}{|l|c|c|c|c|}
\hline Bacterial count & Early childhood Study group n=33 & Caries free Control group n=30 & T-test & p-value \\
\cline { 1 - 3 } Minimum & 111 & 31 & \multirow{2}{*}{24.723} \\
\cline { 1 - 4 } Maximum & 220 & 50.333 & \multirow{2}{*}{$0.000 * *$} \\
Mean & 174.545 & 13.901 & \\
SD & 24.102 & 2.538 & \\
\hline
\end{tabular}

*Highly significant at $\mathrm{P} \leq 0.001$

Table 1 illustrate the viable count of M.S among E.C.C study group and healthy control group.

The results demonstrated that the viable count of M.S was higher in study group than control group with highly significant differences

The results of this study were in agreement with other researchers who also found that MS.. is associated with E.C.C (E.C.C children had more colonies) ${ }^{(17)}$

Other researchers were also in agreement with the present study (18)(19)

Is well-known that M.S. IS the causative microorganism in the development of dental caries because they drop the plaque $\mathrm{pH}$ and produce acids from carbohydrates and survive in the acidic environment. ${ }^{(20)}$
M.S. constitutes about $60 \%$ of cultivable flora of dental plaque obtained from preschool children with $\mathrm{ECC}^{(21)}$. Horizontal and vertical transmission of microbes can be seen. Horizontal transmission occurs between siblings and care givers ${ }^{(22,23)}$. Vertical transmission is also known as mother to child transmission ${ }^{(24)}$. Poor maternal oral hygiene and sugar exposure increases chances of vertical transmission ${ }^{(25)}$.

In appropriate feeding practice can prolong the exposure of teeth to fermentable carbohydrates which in turn may aggravate the chances of ECC ${ }^{(26)}$. Also Bottle feeding during bedtime or sleeping ${ }^{(27)}$ is the most important cause of ECC and hence also known as nursing bottle caries, baby bottle caries. Frequent exposure to sugar, frequent snacking, taking sweetened drinks to bed, sharing foods with adults, as well as maternal caries status, oral hygiene and dietary habits predispose to early $S$. mutans colonization and establishment of its high counts ${ }^{(26)}$.

Table 2: Salivary mean level of histatin 5 in study and control groups

\begin{tabular}{|l|c|c|c|c|}
\hline Salivary histatin 5 & Early childhood Study group n=33 & Caries free Control group n=30 & T-test & \multirow{2}{*}{ p-value } \\
\cline { 1 - 3 } Minimum & 16.538 & 5.907 & \multirow{2}{*}{9.378} \\
\cline { 1 - 3 } Maximum & 43.823 & 22.303 & \multirow{2}{*}{$0.000 * *$} \\
Mean & 24.514 & 11.496 & \\
SD & 6.542 & 4.056 & \\
\hline
\end{tabular}

*Highly significant at $\mathrm{P} \leq 0.001$

Table 2 illustrates salivary levels of histatin 5 in E.C.C. group and healthy control group, the results showed that the levels of histatin5 was higher in E.C.C. group compared with healthy control group and there were highly statistical differences between the two groups 
These results are in agreement with the results of other researchers ${ }^{(28),(29)}$ Increased activity of HST-5 was observed in wide $\mathrm{pH}$ range. However, in low $\mathrm{pH}$ (with presence of caries dental changes) protonation of histidine residues occurs, additionally increasing the antimicrobial force ${ }^{(30)}$.

Histatins are a group of small, cationic, histidinerich peptides secreted by human

The increased level of histatin 5 may be explained by the fact that high-intensity caries is associated with increased levels of some salivary components (histatin-5) that possess strong bactericidal or bacteriostatic effects resulting in aggregation of oral bacteria and their clearance from the oral cavity, ${ }^{(29)}$.

\section{Conclusion}

Salivary histatin 5 level in saliva of children can be used as diagnostic tool or marker for the prediction of caries risk.

\section{Conflict of Interest: None}

\section{Funding: Self}

Ethical Clearance: Not required

\section{References}

1. Hemadi A., Huang R., Zhou Y. and Zou J.; Salivary proteins and microbiota as biomarkers for early childhood caries risk assessment. International Journal of Oral Science; Nov. 2017: 9 (11): e1

2. K.R. Phipps, T.L. Ricks, M.C. Manz, P. Blahut, "Prevalence and severity of dental caries among American Indian and Alaska native preschool children, “ J. Public. Health Dent., 2012. vol. 72, pp. 208-215.

3. Bansode P., Pathak S., Wavdhane M.B., BirageP. Salivary Biomarkers of Dental Caries -A Review Article IOSR Journal of Dental and Medical Sciences. January 2019; Volume 18, Issue 1 Ver. 1, PP 52-58.

4. Kawashita Y, Kitamura M, Saito T: Early childhood caries. Int J Dent 2011, 1-7

5. Guo L, Shi W: Salivary biomarkers for caries risk assessment. Natl Inst Health, 2013; 41, 107-118.

6. Loesche WJ: Role of Streptococcus mutans in human dental decay. 1986; Microbiol Rev 50, 353380 .
7. Roman C, Rivera A, Santellan R, Teutle B: Immunogenic antigens from Streptococcus mutans which stimulate secretory Iga response from parotid saliva in children with caries. World Appl Sci J; 2013: 28, 297-303.

8. Bachtiar E. W, Gultom F. P., Rahmasari A, and Bachtiar B. M. Mutans Streptococci counts from saliva and its protein profile in early childhood caries; Interv Med Appl Sci.; 2018 Dec; 10(4): 222-225.

9. Benitez-Paez A., Belda-Ferre P., Simón-Soro A., Mira A.: Microbiota diversity and gene expression dynamics in human oral biofilms. BMC Genomics, 2014; 15: 311-323.

10. Featherstone JD. The science and practice of caries prevention. J Am Dent Assoc 2000; 131 (7): 887899.

11. C. Lang, M. Böttner, C. Holz, M. Veen, M. Ryser, A. Reindl, M. Pompejus, J.TanzerSpecific Lactobacillus/Mutans Streptococcus coaggregation J. Dent. Res., 89 (2010), pp. 175-179

12. W. Krzyściak, A. Jurczak, J. Piątkowski, D. Kościelniak, L. Gregorczyk-Maga, L. Kołodziej, A. Monika, A. Papież, D. Olczak-KowalczykEffect of histatin-5 and lysozyme on the ability of Streptococcus mutans to formbiofilms in in vitro conditions Adv. Hygiene Exp. Med., 69 (2015); pp. 1056-1066

13. Wyne A. Prevalence and risk factors of nursing caries in Adelaide, South Australia. Pediatr Dent (1999) 9:31-6.

14. World health organization (who) basic survey method 5th edition 2013.

15. Navazesh $M$ and Kumer SK. Measuring salivary flow. J. AM. D. Ass.; 2008; 139: 35-40.

16. MUSA, HT. Salivary Lysozyme, Secretory IgA and the Mutans Streptococci Level in Children with Early Childhood Caries. Master thesis, College of Dentistry/Baghdad University. 2018. p11 - 12

17. BACHTIAR, EW., GULTOM, FP., RAHMASARI, A., BACHTIAR, BM Mutans Streptococci counts from saliva and its protein profile in early childhood caries. Interv Med Appl Sci, . 2018. 10(4),222-225

18. NADA J, SACHDEV V., SANDHU M. \& DEEPSINGH-NANDA K. Correlation between dental caries experience and mutans streptococci counts using saliva and plaque as microbial risk indicators in 3-8 year old children. A cross Sectional study. 
Journal of clinical and experimental dentistry, 2015. 7, e114.

19. MA, C., CHEN, F., ZHANG, Y., SUN, X., TONG, P., SI, Y \& ZHENG, S. Comparison of oral microbial profiles between children with severe early childhood caries and caries-free children using the human oral microbe identification microarray. PLoS One, 2015. 10(3), e0122075.

20. Kumar1 B., Narayana1 H., Murthy1 B., Mathew1 S., Damodhar2 P., Kumar2 S. Indian jornal of dental research. Isolation and genetic characterization of mutans streptococci associated with dental caries in rural field practice of a dental institution: In vivo study. 2019: $30: 6:$ :889-893

21. Tanner AC., et al. "The microbiota of young children from tooth and tongue samples". Journal of Dental Research 81.1 (2002): 53-57.

22. Wan AK., et al. "A longitudinal study of Streptococcus mutans colonization in infants after tooth eruption". Journal of Dental Research 82.7 (2003): 504-508.

23. Kozai K., et al. "Intrafamilial distribution of mutans streptococci in Japanese families and possibility of father-to-child transmission". Medical Microbiology and Immunology 43.2 (1999): 99106.
24. Berkowitz RJ and Jones P. "Mouth-to-mouth transmission of the bacterium Streptococcus mutans between mother and child". Archives of Oral Biology 30.4 (1985): 377-379.

25. Berkowitz RJ. "Mutans streptococci: acquisition and transmission". Pediatric Dentistry 28.2 (2006): 106-109.

26. Paglia L., et al. "Familial and dietary risk factors in Early Childhood Caries". European Journal of Paediatric Dentistry 17.2 (2016): 93-99.

27. Twetman S., et al. "Infant oral health". Dental Clinics of North America 44.3 (2000): 487-505

28. JurczakA.,Koscielniak D.,papiez M., vyhouskaya p., Krzysciak W., A study on $\beta$ - defensin- 2 and histatin-5 as adiagnostic marker of early childhood caries progression.Biol. Res., 2015,48,61

29. Gornowiez.A.,TokajukG.,BielawskaA.,Macior kowskaE.,JablonskiR., Wojcicka A., et al., the assessment of SIgA, histatin-5, and lactoperoxidase level in saliva of adolescents with dental caries,med. Sci. Monit.,2014, 20,1095-1100

30. Melino S, Santone C, Di Nardo P, Sarkar B. Histatins: salivary peptides with copper (II) and zinc (II)-binding motifs. Perspectives for biomedical applications. FEBS J. 2014; 281: 657-72. 